\title{
Two decision aids for mode of delivery among women with previous caesarean section: randomised controlled trial
}

\author{
Alan A Montgomery, senior lecturer in primary care research, ${ }^{1}$ Clare L Emmett, trial coordinator, ${ }^{1}$ Tom \\ Fahey, professor of general practice, ${ }^{2}$ Claire Jones, research assistant, ${ }^{3}$ lan Ricketts, professor of assistive \\ systems and healthcare computing, ${ }^{3}$ Roshni R Patel, specialist registrar in obstetrics and gynaecology, ${ }^{4}$ \\ Tim J Peters, professor of primary care health services research, ${ }^{1}$ Deirdre J Murphy, professor of obstetrics, ${ }^{5}$ \\ on behalf of the DiAMOND Study Group
}

$\overline{{ }^{1} \text { Department of Community Based }}$ Medicine, University of Bristol, Bristol BS8 2AA

${ }^{2}$ Department of General Practice, Royal College of Surgeons in Ireland, Mercer's Medical Centre, Dublin 2, Republic of Ireland, and Tayside Centre for General

Practice, University of Dundee,

Dundee

${ }^{3}$ School of Computing, University of Dundee, Queen Mother Building, Dundee

${ }^{4}$ Academic Unit of Obstetrics and Gynaecology, University of Bristol, St Michael's Hospital, Bristol

${ }^{5}$ Academic Department of Obstetrics and Gynaecology, Trinity College Dublin, Coombe Women's Hospital, Dublin 8, Republic of Ireland, and Department of Obstetrics and Gynaecology, University of Dundee, Ninewells Hospital, Dundee

Correspondence to: A Montgomery alan.a.montgomery@bristol.ac.uk

doi: 10.1136/bmj.39217.671019.55

\section{ABSTRACT}

Objectives To determine the effects of two computer based decision aids on decisional conflict and mode of delivery among pregnant women with a previous caesarean section.

Design Randomised trial, conducted from May 2004 to August 2006.

Setting Four maternity units in south west England, and Scotland.

Participants 742 pregnant women with one previous lower segment caesarean section and delivery expected at $\geq 37$ weeks. Non-English speakers were excluded. Interventions Usual care: standard care given by obstetric and midwifery staff. Information programme: women navigated through descriptions and probabilities of clinical outcomes for mother and baby associated with planned vaginal birth, elective caesarean section, and emergency caesarean section. Decision analysis: mode of delivery was recommended based on utility assessments performed by the woman combined with probabilities of clinical outcomes within a concealed decision tree. Both interventions were delivered via a laptop computer after brief instructions from a researcher.

Main outcome measures Total score on decisional conflict scale, and mode of delivery.

Results Women in the information programme (adjusted difference $-6.2,95 \%$ confidence interval -8.7 to -3.7 ) and the decision analysis $(-4.0,-6.5$ to -1.5$)$ groups had reduced decisional conflict compared with women in the usual care group. The rate of vaginal birth was higher for women in the decision analysis group compared with the usual care group (37\% v 30\%, adjusted odds ratio 1.42 , 0.94 to 2.14 ), but the rates were similar in the information programme and usual care groups.

Conclusions Decision aids can help women who have had a previous caesarean section to decide on mode of delivery in a subsequent pregnancy. The decision analysis approach might substantially affect national rates of caesarean section.

Trial Registration Current Controlled Trials ISRCTN84367722.

\section{INTRODUCTION}

Caesarean section has become an increasingly common method of delivery. From 1980 to 2001 the rate in the United Kingdom increased from $9 \%$ to $21 \%$ of all births ${ }^{1}$ and was most recently reported as 23\%. ${ }^{2}$ Similar increases have been reported in the United States and Australia. ${ }^{34}$ An evaluation of caesarean sections by the American College of Obstetricians and Gynecologists reported that first time mothers with term singleton cephalic pregnancies and women with a previous caesarean section account for the greatest increase in rates of caesarean section and much of the variation between institutions. ${ }^{5}$ Higher rates of caesarean delivery are associated with increased maternal and neonatal morbidity. ${ }^{6}$

Rising rates of caesarean deliveries are assumed to have been driven by obstetricians, reflecting medicolegal concerns about vaginal birth after previous caesarean section (VBAC), vaginal breech delivery, and fetal distress in labour. In contrast, over a similar time period there has been increased emphasis on involvement of patients in making medical decisions. ${ }^{7-9}$ The traditional paternalistic model of care is based on the premise that the obstetrician knows best and by taking the lead on decisions could reduce anxiety and risk for the mother and her baby. ${ }^{10}$ The shared model of medical decision making, in which clinician and patient exchange information, reveal preferences for treatment, and jointly come to a decision, is now promoted in preference to other models. ${ }^{10-12}$ Decision aids are designed to help people select between various treatment strategies by providing information on the options and outcomes relevant to a person's health. A Cochrane review has reported that decision aids can improve knowledge and realistic expectations, reduce decisional conflict, and increase active participation in decision making. ${ }^{13}$ A recent consensus process identified key aspects of quality of patients' decision aids relating to content, development, and effectiveness. ${ }^{14}$

Determining the optimal mode of delivery for a woman who has experienced a previous caesarean section requires consideration of the risks and benefits of 
repeat section and of vaginal birth after previous caesarean section alongside her views and preferences for a particular type of birth experience. ${ }^{10}$ While women may want and be given a larger role in decision making, this may be without access to comprehensive and balanced information about possible risks and

\section{$\overline{\text { Table } 1 \text { | Characteristics of women in trial at baseline. Figures are numbers (percentages) unless }}$} stated otherwise

\begin{tabular}{|c|c|c|c|}
\hline & Usual care $(n=247)$ & Information $(\mathrm{n}=250)$ & $\begin{array}{l}\text { Decision analysis } \\
\qquad(\mathrm{n}=245)\end{array}$ \\
\hline Mean (SD) age (years) & $32.4(4.6)$ & $32.8(4.7)$ & $32.5(4.8)$ \\
\hline Mean (SD) gestational age (weeks) & $18.7(4.4)$ & $19.2(4.5)$ & $19.0(4.4)$ \\
\hline \multicolumn{4}{|l|}{ Mean (SD) deprivation: } \\
\hline Townsend score (England) & $-0.53(2.7)(n=175)$ & $-0.56(2.6)(n=172)$ & $-0.35(2.9)(n=175)$ \\
\hline Carstairs index (Scotland) & $-0.96(3.5)(n=61)$ & $0.01(4.2)(n=63)$ & $-0.40(4.4)(n=62)$ \\
\hline \multicolumn{4}{|l|}{ Hospital: } \\
\hline Ninewells & $61(25)$ & $63(25)$ & $62(25)$ \\
\hline Southmead & $119(48)$ & $118(47)$ & $118(48)$ \\
\hline St Michaels & $63(26)$ & $63(25)$ & $61(25)$ \\
\hline Weston & $4(2)$ & $6(2)$ & $4(2)$ \\
\hline \multicolumn{4}{|l|}{ Household income (£1000): } \\
\hline$\ll 20$ & $42(18)$ & 44 (19) & $48(20)$ \\
\hline$£ 20-30$ & $53(23)$ & $57(24)$ & $49(21)$ \\
\hline$£ 30-40$ & $51(22)$ & $46(19)$ & 44 (19) \\
\hline$£ 40-50$ & $43(18)$ & $37(16)$ & $46(19)$ \\
\hline 㓉0 & $46(20)$ & $52(22)$ & $50(21)$ \\
\hline \multicolumn{4}{|l|}{ Highest educational qualification: } \\
\hline None & $12(5)$ & $10(4)$ & $7(3)$ \\
\hline GCSE/NVQ1-3 & $99(40)$ & $92(37)$ & $97(40)$ \\
\hline A level/HND & $42(17)$ & 47 (19) & $36(15)$ \\
\hline Degree & $92(38)$ & $97(39)$ & $103(42)$ \\
\hline \multicolumn{4}{|l|}{ Parity: } \\
\hline 1 & 225 (91) & 227 (92) & $217(89)$ \\
\hline 2 & $16(6)$ & $11(4)$ & $19(8)$ \\
\hline$\geq 3$ & $6(2)$ & $10(4)$ & $7(3)$ \\
\hline \multicolumn{4}{|l|}{ Previous caesarean section: } \\
\hline Elective & $62(25)$ & $55(22)$ & $49(20)$ \\
\hline Emergency & $184(75)$ & $192(78)$ & $193(80)$ \\
\hline \multicolumn{4}{|l|}{ Living with partner: } \\
\hline No & $11(5)$ & $12(5)$ & $11(5)$ \\
\hline Yes & $232(95)$ & $234(95)$ & $232(95)$ \\
\hline Mean (SD) decisional conflict scale & $38.0(17.1)(n=237)$ & $40.2(16.6)(n=237)$ & $37.8(17.2)(n=234)$ \\
\hline
\end{tabular}

(total)

Mean (SD) decisional conflict subscales:

\begin{tabular}{llll}
\hline Uncertainty & $33.7(17.9)(n=245)$ & $35.6(18.0)(n=248)$ & $33.3(17.2)(n=241)$ \\
\hline Informed & $47.5(25.5)(n=244)$ & $47.5(27.2)(n=246)$ & $47.2(27.1)(n=239)$ \\
\hline Clear values & $37.3(22.0)(n=245)$ & $39.6(20.9)(n=248)$ & $36.9(20.8)(n=242)$ \\
\hline Supported & $38.9(22.5)(n=243)$ & $43.1(21.4)(n=245)$ & $40.7(22.4)(n=240)$ \\
\hline Stick with decision & $35.1(18.8)(n=244)$ & $37.4(17.5)(n=241)$ & $34.0(18.7)(n=238)$ \\
\hline Anxiety & $35.7(12.1)(n=238)$ & $35.8(11.8)(n=236)$ & $35.6(11.1)(n=234)$ \\
\hline Knowledge & $47.2(19.7)(n=242)$ & $45.9(19.6)(n=245)$ & $46.1(19.3)(n=239)$ \\
\hline
\end{tabular}

Total score on decisional conflict scale:

\begin{tabular}{lccc}
\hline$\leq 37.5$ & $126(53)$ & $105(44)$ & $118(50)$ \\
\hline $\mathbf{3 7 . 5}$ & $111(47)$ & $132(56)$ & $116(50)$ \\
\hline Preferred mode of delivery: & & & \\
\hline Vaginal & $111(45)$ & $112(45)$ & $111(45)$ \\
\hline Elective caesarean & $53(21)$ & $52(21)$ & $50(20)$ \\
\hline Unsure & $83(34)$ & $86(34)$ & $84(34)$ \\
\hline
\end{tabular}

benefits. ${ }^{1516}$ There is also the potential for selective use of risk based information that may increase anxiety and unduly influence the decision making process. ${ }^{17}$

\section{Objectives}

We investigated the effects of two computer based decision aids (an information programme and individualised decision analysis) on decisional conflict and actual mode of delivery among a group of pregnant women with one previous caesarean section. We also explored effects on knowledge, anxiety, and satisfaction with the decision.

\section{METHODS}

\section{Participants}

The sample comprised pregnant women with one previous lower segment caesarean section, no current obstetric problems, and delivery expected at $\geq$ 37 weeks. Women of all parities were included, but their most recent delivery must have been a caesarean section. We excluded women with limited ability to speak or understand English.

\section{Recruitment setting and procedures}

Three maternity units in south west England and one unit in Scotland recruited women from May 2004 to January 2006. The rates of caesarean section for these units ranged from $22 \%$ to $25 \%$, which is representative of the UK national rate. A research midwife recruited women during their initial booking visit at the antenatal clinic, usually at around 10-20 weeks' gestation. Women received an information sheet, a consent form, and a baseline questionnaire.

\section{Randomisation}

After administering the baseline questionnaire and receiving written informed consent, the trial coordinator randomised women to one of three groups. Allocation was stratified by maternity unit and preferred mode of delivery at baseline and blocked by using ran domly permuted and selected blocks of sizes $6,9,12$, and 15 . One member of the study team (AAM) generated the randomisation sequence by computer, and another member of staff with no other involvement in the trial performed the allocation.

\section{Interventions}

Both interventions were computer based. Women allocated to receive an intervention had an appointment with a researcher to allow the decision aid to be delivered with a laptop computer, usually in the woman's own home. The appointment started with a brief training session to ensure the woman was comfortable using a computer and able to navigate through the decision aid. After the training session the woman was left to navigate through the programme at her leisure, spending as much time as she needed on each section and with the opportunity to repeat sections if she wished. The protocol and interventions are described in detail elsewhere. ${ }^{1819}$ 


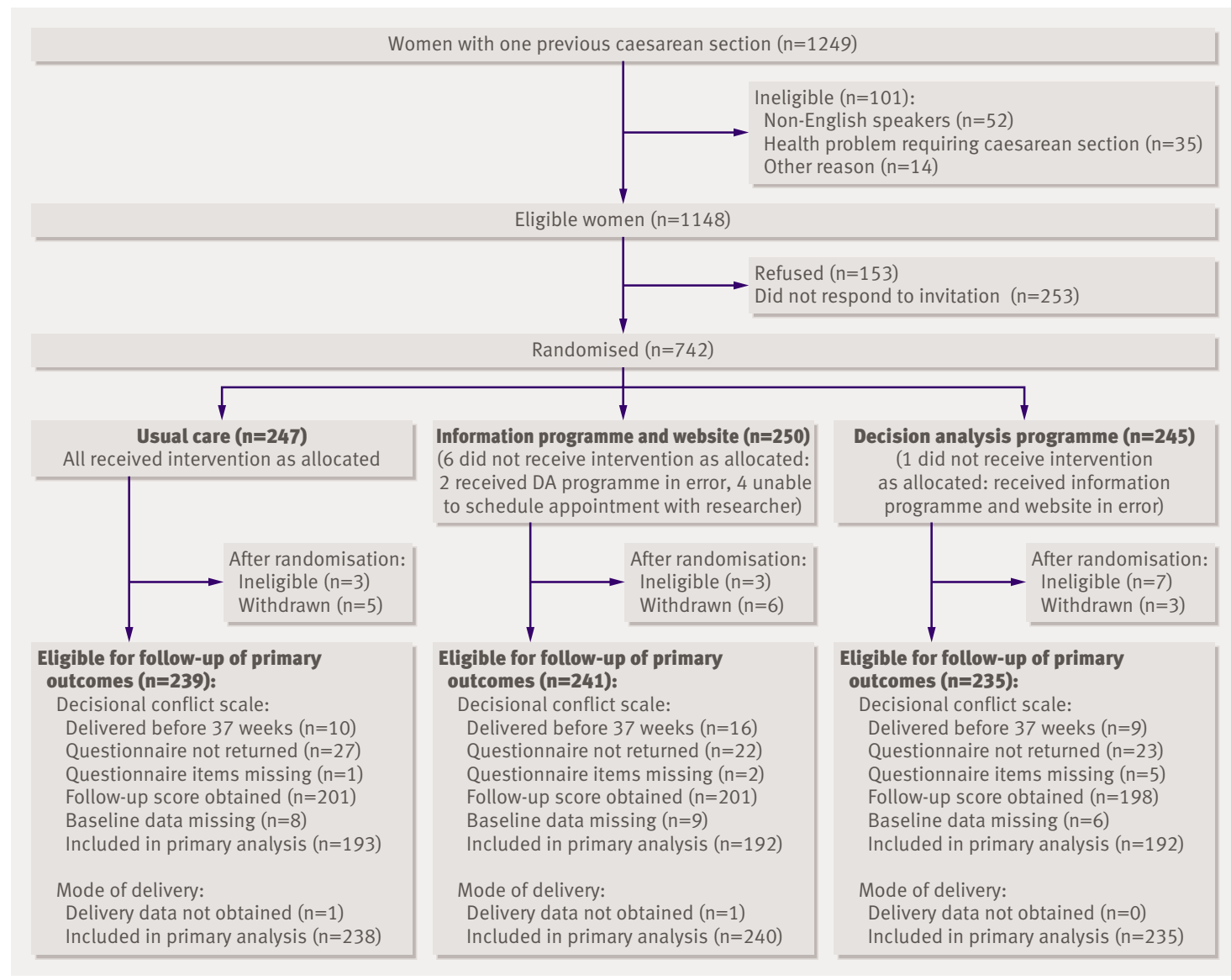

Flow of women through the study

Usual care - This comprised the usual level of care given by the obstetric and midwifery team. Women in the two intervention groups also received usual care.

Information programme - This provided information about the outcomes associated with planned vaginal delivery, elective caesarean section, and emergency caesarean section, including descriptions of possible health outcomes for both mother and baby. Two of the research team (DJM, RRP) obtained the probabilities of these outcomes from a literature review to reflect the best available evidence at the time. The programme gave the probabilities of having and not having the event, in both numerical and pictorial format. ${ }^{20}$ At the end of the appointment, women received a password that allowed them to access the information programme again through the internet, providing an opportunity to review the information with their partner. We did not provide hard copies of information to avoid the potential for wider dissemination and cross contamination across the different groups.

Decision analysis - The steps involved in decision analysis are described in detail elsewhere. ${ }^{21}$ Firstly, women were given information about the outcomes associated with planned vaginal delivery, elective caesarean section, and emergency caesarean section. This comprised descriptions, but not explicit probabilities, of outcomes for both mother and baby. Secondly, women were required to consider the value they attached to possible outcomes by rating each on a visual analogue scale from 0 to 100 . Though these ratings are not strictly equivalent to utility values, we considered this to be a pragmatic method of assessment and the information produced to be sufficient for this study. We combined the values with the probabilities of each outcome in a decision tree to produce a recommended "preferred option" based on maximised expected utility. Women received a computer printout of the outcome of the decision analysis and were encouraged to discuss this with their midwife or obstetrician at subsequent antenatal visits.

Both intervention groups-Women in both intervention groups were contacted again by letter at 35 weeks' gestation to encourage discussion of the intervention with their obstetrician or midwife, or both, when they attended the clinic at 36-37 weeks to finalise their birth plan. Stickers in the woman's records alerted health professionals to her participation in the study.

\section{Outcome measures}

There were two primary outcomes and eight secondary outcomes: 


\begin{tabular}{|c|c|c|c|}
\hline & Usual care & Information & Decision analysis \\
\hline Mean (SD) total score on DCS & $27.8(14.6)(n=201)$ & $22.5(13.2)(n=201)$ & $23.6(15.1)(n=198)$ \\
\hline \multicolumn{4}{|l|}{ No (\%) with mode of delivery: } \\
\hline Elective caesarean & $118(50)$ & 117 (49) & 97 (41) \\
\hline Emergency caesarean & $48(20)$ & $53(22)$ & $50(21)$ \\
\hline Vaginal birth & $72(30)$ & $70(29)$ & $88(37)$ \\
\hline
\end{tabular}

Decisional conflict scale-This is a 16 item questionnaire that measures degree of uncertainty about which course of action to take and the main modifiable factors contributing to uncertainty. Previous research indicates that an effect size of $0.3-0.4 \mathrm{SD}$ is meaningful, and that total scores $<25$ or $\geq 37.5$ are associated with decision implementation or delay, respectively. ${ }^{22}$

Actual mode of delivery (vaginal birth $\mathrm{v}$ caesarean section) -The interventions were not designed to promote one mode of delivery over another. Any change in the proportions of vaginal birth or caesarean delivery, however, might have a substantial impact on healthcare providers. The study was therefore powered to detect any such effects.

Secondary outcomes - We investigated anxiety, ${ }^{23}$ knowledge, subscales of the decisional conflict scale ${ }^{22}$ and satisfaction with the decision. ${ }^{24}$

\section{Collection of follow-up data}

The primary follow-up for questionnaire based outcomes was at 37 weeks' gestation. This was timed for three to seven days after a scheduled clinic visit at around 36 weeks when women met their obstetric team to discuss and finalise their plans for delivery. We obtained data on mode of delivery from hospital maternity records and assessed satisfaction with the decision in a further follow-up questionnaire about six weeks after delivery.

\section{Sample size}

Differences of 0.3-0.4 SD are important for the total score of the decisional conflict scale, and differences of this magnitude are feasible for interventions of this kind. ${ }^{25}$ With regard to mode of delivery, UK data

\begin{tabular}{|c|c|c|c|}
\hline & Crude figure & Adjusted figure* $(95 \% \mathrm{Cl})$ & $\mathrm{P}$ value $†$ \\
\hline \multicolumn{4}{|c|}{ Difference between groups in total score on DCS } \\
\hline Information $v$ usual care & -5.3 & $-6.2(-8.7$ to -3.7$)$ & $<0.001$ \\
\hline Decision analysis $v$ usual care & -4.2 & $-4.0(-6.5$ to -1.5$)$ & 0.005 \\
\hline Decision analysis $v$ information & 1.1 & $2.2(-0.3$ to 4.7$)$ & 0.19 \\
\hline \multicolumn{4}{|c|}{ Odds ratio for vaginal $v$ elective/emergency caesarean section } \\
\hline Information $v$ usual care & 0.95 & $0.93(0.61$ to 1.41$)$ & $>0.9$ \\
\hline Decision analysis $v$ usual care & 1.38 & $1.42(0.94$ to 2.14$)$ & 0.22 \\
\hline Decision analysis $v$ information & 1.45 & 1.53 (1.01 to 2.30$)$ & 0.11 \\
\hline
\end{tabular}

DCS=decisional conflict scale.

*Adjusted for preferred mode of delivery at baseline, hospital, and value of outcome variable at baseline (for DCS only).

†Adjusted for multiple comparisons with Tukey's procedure. indicate that about $33 \%$ of women with a previous caesarean section are delivered vaginally, ${ }^{1}$ and a previous trial of counselling observed that $51 \%$ of women achieved vaginal delivery for the trial groups overall. ${ }^{26}$ A change from $30-33 \%$ to $51 \%$ corresponds to an odds ratio of about 2.1-2.4, and this would certainly be considered as clinically important.

With two sided $1 \% \alpha$, a total sample size of 600 provides $82-99 \%$ power to detect a standardised difference of 0.35-0.5 in total score on the decisional conflict scale between the groups, and 84-95\% power to detect odds ratios of 2.1-2.4 in women achieving vaginal delivery. A pairwise $\alpha$ of $1 \%$, corrected for multiple comparisons between groups using Tukey's procedure, yields an overall study $\alpha$ of $3.4 \%$. To allow for preterm deliveries, malpresentations, and losses to follow-up, we originally aimed to recruit 660 women to the trial However, this underestimated the number of participants for whom we could not obtain follow-up data so we increased the number to 740 and extended the recruitment period once realistic estimates of attrition emerged.

\section{Statistical analysis}

We used descriptive statistics to characterise the group of individuals recruited to the trial in relation to those eligible and to investigate comparability of the groups at baseline. The primary analyses comprised three pairwise intention to treat comparisons between usual care and the information and decision analysis groups for each of the two primary outcomes. We used appropriate (that is, standard or logistic) multivariable regression models, adjusted for maternity unit, initial preference regarding mode of delivery, and value of the outcome variable at baseline. We used Tukey's procedure to adjust P values. Secondary outcomes were analysed in the same way and without any additional adjustment for multiple comparisons between groups.

We used preplanned subgroup analyses with appropriate interaction terms in the regression models to ascertain any differential effects of the interventions on the two primary outcomes according to previous caesarean section occurring before or after labour; previous successful vaginal delivery; and preferred mode of delivery at baseline.

\section{RESULTS}

\section{Participants}

Of 1148 women invited to participate in the trial, 742 were randomised, and primary outcome data were obtained for $600(81 \%)$ for the decisional conflict scale and $713(96 \%)$ for mode of delivery (figure). Women who consented to participate were slightly older (32.5 $v 31.9$ years, $\mathrm{P}=0.05)$ and less deprived $(\mathrm{P}=0.02)$ than those who did not take part. Table 1 shows characteristics of the study sample and outcome data at baseline. Overall mean (SD) age at randomisation was 32.6 (4.7) years, and mean gestational age was 19.0 (4.4) weeks. Most women $(91 \%)$ had had only one previous live delivery. 


\begin{tabular}{|c|c|c|c|}
\hline \multicolumn{4}{|c|}{ No (\%) with total score on DCS: } \\
\hline$\geq 25$ & $127(63)$ & $106(53)$ & $109(55)$ \\
\hline$<25$ & $74(37)$ & $95(47)$ & $89(45)$ \\
\hline \multicolumn{4}{|c|}{ Mean (SD) score on DCS subscales: } \\
\hline Informed & $35.8(22.7)(n=203)$ & $32.4(23.2)(n=203)$ & $35.1(25.6)(n=199)$ \\
\hline Clear values & $24.1(15.8)(n=203)$ & $16.4(12.2)(n=203)$ & $17.6(13.2)(n=201)$ \\
\hline Supported & $28.5(18.7)(n=201)$ & $22.2(13.4)(n=203)$ & $22.2(16.5)(n=200)$ \\
\hline Stick with decision & $24.7(14.7)(n=203)$ & $21.6(14.9)(n=201)$ & $22.5(16.1)(n=200)$ \\
\hline
\end{tabular}

Overall mean (SD) score on the decisional conflict scale at baseline was $38.6(17.0)$ on a scale of $0-100$, with higher scores indicating greater decisional conflict. Scores exceeding 37.5 are associated with delay in decision making or feeling unsure about implementation. Around twice as many women had a preference for a vaginal delivery compared with elective caesarean section, but over a third were uncertain about their preferred mode of delivery (table 1). Of 250 women allocated to the information group, 59 $(24 \%)$ accessed the intervention again through the website at least once.

\section{Primary analyses}

Decisional conflict-Total decisional conflict was reduced in all three groups at follow-up compared with baseline (table 2). Both interventions reduced decisional conflict more than usual care, with effect sizes of $0.31 \mathrm{SD}(95 \%$ confidence interval 0.22 to $0.51)$ and $0.24 \mathrm{SD}(0.09$ to 0.39$)$, respectively, for information programme and decision analysis (tables 1 and 3). There was no evidence of any difference between the intervention groups (table 3).

Mode of delivery - A higher proportion of women in the decision analysis group (37\%) delivered vaginally compared with in the usual care $(30 \%)$ and information programme groups (29\%) (table 2). The lower 95\% confidence limits for the odds ratios, however, are consistent with no difference between decision analysis and the other groups (table 3), and the observed increased rate of vaginal birth in this group could be a chance finding.

\section{Secondary analyses}

Decisional conflict, anxiety, knowledge, and satisfaction Scores of $<25$ on the decisional conflict scale are associated with implementing decisions. ${ }^{22}$ Women in the information programme and decision analysis groups were more likely than women in usual care to report decisional conflict scores below this level (tables 4 and 5). Anxiety and knowledge scores were higher in all three groups at 37 weeks' gestation compared with baseline (table 4), though women in the two intervention groups had lower anxiety scores and higher knowledge scores that those in the usual care group (table 5). In all women the overall satisfaction with the decision measured six weeks after delivery was 4.3 out of a possible 5. Compared with usual care, satisfaction was higher in the decision analysis group but not in the information programme group (table 5). There were no differences between the interventions for anxiety, knowledge, or satisfaction (table 5).

Subgroup analyses - The effects of the interventions on total scores on the decisional conflict scale at 37 weeks' gestation did not differ according to whether the previous caesarean section was elective or emergency $(\mathrm{P}=0.70)$ or the preferred mode of delivery at baseline $(\mathrm{P}=0.66)$. The effect may differ, however, depending on whether women had had a previous vaginal delivery: the information programme seemed to have a greater effect among women who had successfully delivered vaginally previously $(\mathrm{P}=0.07$ ) (table 6$)$.

For actual mode of delivery, there was no evidence of any interaction between study group and type of previous caesarean section $(\mathrm{P}=0.97)$, previous successful vaginal delivery $(\mathrm{P}=0.27)$, or preferred mode of delivery at baseline $(\mathrm{P}=0.35)$.

\section{DISCUSSION}

\section{Summary of main findings}

Computer based decision aids can reduce decisional conflict among pregnant women with one previous caesarean section. Both decision aids in our study were associated with greater knowledge and less anxiety compared with usual care. The intervention based on decision analysis was associated with a higher proportion of women achieving a vaginal birth.

\section{Strengths and limitations of the study}

We achieved a high rate of recruitment and a low loss to follow-up, reflecting the importance placed by women and health professionals on this aspect of obstetric care. The study was comparatively large and the 


\begin{tabular}{|c|c|c|c|}
\hline & Crude figure & Adjusted* figure $(95 \% \mathrm{Cl})$ & $P$ value \\
\hline \multicolumn{4}{|l|}{ Difference } \\
\hline \multicolumn{4}{|l|}{ Anxiety: } \\
\hline Information $v$ usual care & -3.6 & $-3.0(-5.2$ to -0.7$)$ & 0.010 \\
\hline Decision analysis $v$ usual care & -3.4 & $-2.8(-5.0$ to -0.5$)$ & 0.016 \\
\hline Decision analysis $v$ information & 0.2 & $0.2(-2.1$ to 2.4$)$ & 0.87 \\
\hline \multicolumn{4}{|l|}{ Knowledge: } \\
\hline Information $v$ usual care & 12.3 & $12.8(9.7$ to 15.9$)$ & $<0.001$ \\
\hline Decision analysis $v$ usual care & 10.6 & $11.2(8.1$ to 14.2$)$ & $<0.001$ \\
\hline Decision analysis $v$ information & -1.7 & $-1.6(-4.7$ to 1.4$)$ & 0.30 \\
\hline \multicolumn{4}{|l|}{ Satisfaction with decision: } \\
\hline Information $v$ usual care & 0.06 & $0.06(-0.06$ to 0.19$)$ & 0.31 \\
\hline Decision analysis $v$ usual care & 0.14 & $0.14(0.02$ to 0.27$)$ & 0.022 \\
\hline Decision analysis $v$ information & 0.08 & $0.08(-0.04$ to 0.20$)$ & 0.20 \\
\hline \multicolumn{4}{|l|}{ Odds ratio } \\
\hline \multicolumn{4}{|c|}{ Total score on DCS as binary $(<25 v \geq 25)$ : } \\
\hline Information $v$ usual care & 1.54 & $2.04(1.29$ to 3.24$)$ & 0.002 \\
\hline Decision analysis $v$ usual care & 1.40 & 1.54 (0.98 to 2.42$)$ & 0.063 \\
\hline Decision analysis $v$ information & 0.91 & 0.75 (0.48 to 1.18$)$ & 0.22 \\
\hline
\end{tabular}

results are of direct clinical relevance to care of patients. In addition to the usual questionnaire based outcomes, we defined mode of delivery as a primary outcome and powered the trial accordingly. Our target odds ratio of at least 2.1 , in the context of continually rising rates of caesarean section and falling rates of vaginal birth after previous caesarean section, however, was probably overly optimistic, and a larger sample size may have improved the precision around a smaller but still clinically important effect size. The choice of a clinically important effect size is often a matter of judgment, but from the effect observed in our study, use of the decision analysis intervention by women with a previous caesarean section could result in about 4000 fewer caesarean sections a year in England and Wales. ${ }^{12}$

A further potential limitation was the way in which women accessed the interventions with a laptop computer provided by a study researcher. An alternative would have been to provide the decision aids exclusively through the internet. However, we considered it necessary to ensure that all women allocated to receive an intervention had the opportunity to use it at least once. We will be exploring implementation issues further with a sample of health professionals. Ideally, women who do not speak English should be able to access these interventions.

\section{Comparison with existing literature}

For decisional conflict and knowledge, our findings are consistent with those of a Cochrane review of decision aids for patients developed and evaluated in various settings and conditions. ${ }^{13}$ The $95 \%$ confidence intervals for decisional conflict as a continuous outcome include effect sizes considered important, and 8-10\% more women in the intervention groups reported total decisional conflict below a threshold score of 25, which is associated with implementing decisions. Notably, women in the intervention groups in our study reported reduced anxiety compared with those in usual care. This is an important finding, as detailed descriptions and probability information about obstetric complications might be considered as potentially alarming. Our results show that use of a decision aid early in pregnancy may be able to address many questions and concerns that women have and that this effect persists through to delivery.

For mode of delivery, the results are intriguing. A recent randomised trial of a paper based decision aid for women with a previous caesarean section found a reduction in decisional conflict but no evidence of an effect on mode of delivery. ${ }^{27}$ An earlier comparison of verbal versus leaflet interventions aimed at promoting vaginal birth among women with a previous caesarean section found no difference between groups in terms of mode of delivery but did report an overall higher proportion of women delivering vaginally compared with the national average. ${ }^{26}$ Given the lower confidence limits of the odds ratios in our trial it is certainly possible that this is a chance finding.

\begin{tabular}{|c|c|c|c|}
\hline $\begin{array}{l}\text { Previous } \\
\text { vaginal } \\
\text { delivery }\end{array}$ & Usual care & Information & Decision analysis \\
\hline No & $\begin{array}{c}27.6(14.7) \\
(n=188)\end{array}$ & $\begin{array}{c}23.0(12.9) \\
(n=186)\end{array}$ & $\begin{array}{c}23.5(15.0) \\
(n=180)\end{array}$ \\
\hline Yes & $\begin{array}{c}31.5(13.7) \\
(n=13)\end{array}$ & $\begin{array}{c}17.1(15.4) \\
(n=15)\end{array}$ & $25.3(16.3)(n=18)$ \\
\hline
\end{tabular}




\section{WHAT IS ALREADY KNOWN ON THIS TOPIC}

Pregnant women with a previous caesarean section must decide between planned vaginal birth and elective repeat caesarean section

The optimal approach to decision making in these circumstances is unclear

\section{WHAT THIS STUDY ADDS}

Computer based decision aids can reduce decisional conflict and anxiety and increase knowledge

A decision analysis based approach might result in more women delivering vaginally

The observed difference in rates of vaginal birth, however, is clinically important and warrants consideration. Why should a decision aid influence the mode of delivery? Why should a more complex intervention based on decision analysis be more effective than the simpler information programme? The key elements of decision analysis are the ascertainment of utilities by the woman herself (values placed on possible outcomes) and the provision of a recommended method of delivery by computer printout. Ongoing parallel qualitative work indicates that explicit consideration of personal values attached to potential outcomes challenges women's perceptions of the optimal decision and this may influence their resolve to achieve a vaginal birth The technique combines utility and probability information and recommends the option that gives the best chance of achieving an outcome(s) that is valued. It is more commonly used to inform policy decisions and is not universally supported as an individual decision aid for patients. ${ }^{28}$ Our results add to other empirical evidence that individualised decision analysis is feasible and acceptable and has value as an aid to patients' decision making. ${ }^{252930}$

\section{Implications for practice}

We have shown that women making decisions about mode of delivery after a previous caesarean section benefit from access to computer based decision aids in reducing decisional conflict and anxiety and increasing knowledge. The decision aids could be made readily available through the internet and therefore distributed widely to potential users. Although the content was carefully designed to not favour one mode of delivery over another, even a small absolute change in decisions could have a substantial impact on national rates of caesarean section.

We thank the women who took part in the study. Other members of the Decision Aids for Mode Of Next Delivery (DiAMOND) Study Group are as follows: Julia Frost, Alison Shaw (qualitative study); Peter Gregor (applied computing); Sandra Hollinghurst (economic evaluation); Beverley Lovering, Anne Schlegelmilch, Kate Warren (recruitment); Maureen Macleod, Irene Munro (recruitment, delivery of interventions, data collection); Helen Watson (data collection); and Kav Vedhara (health psychology)

Contributors: AAM (guarantor), TF, and DJM had the original idea for the study and, with TJP, carried out the design. AAM, TF, RRP, TJP, and DJM obtained funding. AAM, CLE, TF, CJ, RRP, IR, TJP, DJM developed the interventions, and CLE was also responsible for data collection. AAM, CLE, and TJP carried out the analysis. AAM and CLE drafted the manuscript, which was revised by TF, CJ, IR, RRP, TJP, and DJM.

Funding: BUPA Foundation. AAM was part supported by a postdoctoral fellowship from the UK Department of Health National Coordinating Centre for Research Capacity Development.

Competing interests: None declared.

Ethical approval: South west multicentre research ethics committee.

1 Royal College of Obstetricians and Gynaecologists Clinical Effectiveness Support Unit. The national sentinel caesarean section audit report London: RCOG Press, 2001.

2 Information Centre for Health and Social Care. NHS maternity statistics, England: 2004-05. London: Information Centre, 2006.

3 Martin JA, Hamilton BE, Menacker F, Sutton PD, Matthews TJ. Preliminary births for 2004: infant and maternal health. 2006. www. cdc.gov/nchs/products/pubs/pubd/hestats/prelimbirths04/ prelimbirths04health.htm.

4 Nassar N, Sullivan E. Australia's mothers and babies 1999. Sydney: Australian Institute of Health and Welfare National Perinatal Statistics Unit, 2001.

5 American College of Obstetricians and Gynecologists. Evaluation of cesarean delivery. Washington, DC: ACOG, 2000.

6 Villar J, Valladares E, Wojdyla D, Zavaleta N, Caroli G, Velazco A, et al. Caesarean delivery rates and pregnancy outcomes: the 2005 WHO global survey on maternal and perinatal health in Latin America. Lancet 2006;367:1819-29.

7 Department of Health. Changing childbirth. Part 1: report of the expert maternity group. London: HMSO, 1993.

8 National Institute for Clinical Excellence. Caesarean section: clinical guideline 13. London: NICE, 2004.

9 Department of Health. Maternity standard, national service framework for children, young people and maternity services. London: DH Publications, 2004.

10 Kalish RB, McCullough LB, Chervenak FA. Decision-making about caesarean delivery. Lancet 2006;367:883-5.

11 Charles C, Whelan T, Gafni A. What do we mean by partnership in making decisions about treatment? BMJ 1999;319:780-2.

12 Coulter A. Paternalism or partnership? BMJ 1999;319:719-20.

13 O'Connor AM, Stacy D, Entwistle V, Llewellyn-Thomas H, Rovner D, Holmes-Rovner M, et al. Decision aids for people facing health treatment or screening decisions. Cochrane Database Syst Rev 2003 (1):CD004131.

14 Elwyn G, O'Connor AM, Stacey D, Volk R, Edwards A, Coulter A, et al. Developing a quality criteria framework for patient decision aids: online international Delphi consensus process. BMJ 2006;333:417.

15 York S, Briscoe L, Walkinshaw S, Lavender T. Why women choose to have a repeat caesarean section. Br J Midwifery 2005;13:440-5.

16 Emmett CL, Shaw ARG, Montgomery AA, Murphy DJ. Women's experience of decision-making about mode of delivery after a previous caesarean section: the role of health professionals and information about health risks. BJOG 2006;113:1438-45.

17 Sur S, MacKenzie IZ. Does discussion of possible scar rupture influence preferred mode of delivery after a caesarean section? J Obstet Gynaecol 2005;25:338-41.

18 Montgomery AA, DiAMOND Study Group. The DiAMOND trial protocol: a randomised controlled trial of two decision aids for mode of delivery among women with a previous caesarean section [ISRCTN84367722]. BMC Pregnancy Childbirth 2004;4;25.

19 Emmett CL, Murphy DJ, Patel R, Fahey T, Jones C, Ricketts IW, et al. Decision making about mode of delivery after previous caesarean section: development and piloting of two computer-based decision aids. Health Expectationswww.blackwell-synergy.com/doi/pdf/ 10.1111/j.1369-7625.2006.00429.x.

20 Edwards A, Elwyn G, Mulley A. Explaining risks: turning numerical data into meaningful pictures. BMJ 2002;324:827-30.

21 Sox HC, Blatt MA, Higgins MC, Marton Kl. Medical decision making. Boston: Butterworth-Heinemann, 1988.

22 Ottawa Health Decision Centre. User manual-decisional conflict scale(s). 2006. http://decisionaid.ohri.ca/docs/Eval_Meas/ User_Manuals/UM_DecConflict2006.pdf.

23 Marteau TM, Bekker H. The development of a six-item short-form of the state scale of the Spielberger state-trait anxiety inventory (STAI) BrJ Clin Psychol 1992;31:301-6.

24 Holmes-Rovner M, Kroll J, Schmitt N, Rovner DR, Breer ML, Rother ML, et al. Patient satisfaction with health care decisions: the satisfaction with decision scale. Med Decis Making 1996;16:58-64.

25 Montgomery AA, Fahey T, Peters TJ. A factorial randomised controlled trial of decision analysis and an information video plus leaflet for newly diagnosed hypertensive patients. Br J Gen Pract 2003;53:446-53.

26 Fraser W, Maunsell E, Hodnett E, Moutquin J-M. Randomized controlled trial of a prenatal vaginal birth after cesarean section 
education and support program. Am J Obstet Gynecol 1997;176:419-25.

27 Shorten A, Shorten B, Keogh J, West S, Morris J. Making choices for childbirth: a randomized controlled trial of a decision-aid for informed birth after caesarean. Birth 2005;32:252-61.

28 Elwyn G, Edwards A, Eccles M, Rovner D. Decision analysis in patient care. Lancet 2001;358:571-4.

29 Bekker HL, Hewison J, Thornton JG. Applying decision analysis to facilitate informed decision making about prenatal diagnosis for
Down syndrome: a randomised controlled trial. Pren Diagn 2004;24:265-75.

30 Dowding D, Swanson V, Bland R, Thompson P, Mair C, Morrison A, et al. The development and preliminary evaluation of a decision aid based on decision analysis for two treatment conditions: benign prostatic hyperplasia and hypertension. Patient Educ Couns 2004;52:209-15.

Accepted: 18 April 2007 